\title{
De Veteranos para os Novatos: Avaliação das Atividades de Recepção aos Calouros Organizadas pelo Grupo PETComp
}

\author{
Daniel Pinto ${ }^{1}$, Eduarda Chagas ${ }^{1}$, Gabriel Costa ${ }^{1}$, Kennedy Nunes ${ }^{1}$, Ricardo Anchieta ${ }^{1}$, \\ Simara Rocha ${ }^{1}$, Anselmo Paiva ${ }^{2}$ e Luis Rivero ${ }^{1,2}$ \\ ${ }^{1}$ Programa de Educação Tutorial do Curso de Ciência da Computação (PETComp) \\ Universidade Federal do Maranhão (DEINF/UFMA) - São Luís - MA - Brasil \\ ${ }^{2}$ Programa de Pós-Graduação em Ciência da Computação (PPGCC), \\ Universidade Federal do Maranhão (UFMA) - São Luís, MA - Brasil \\ \{danielmoreirapinto.ti, eduardamachagas, gjsc1212, \\ kennedy.andersonoficial, ricardoanchieta99, simararocha\}@gmail.com, \\ \{paiva, luisrivero\} @nca.ufma.br
}

\begin{abstract}
Students entering undergraduate courses find it difficult to adapt to the new teaching modality. The Freshman Week event is held by the students of the Computer Science PET group at the Federal University of Maranhão accompanied by teachers as an integration activity for the new students of the Computer Science course. This paper reports the experience of applying various activities in order to clarify the doubts generated by entering the new environment, as well as increasing the visibility of the course contexts. At the end of the activities, the feedback from the students pointed to their usefulness for knowing the opportunities within the university in terms of projects, research and actuation areas, as well as solutions to problems that arose during their execution.
\end{abstract}

Resumo. Alunos ingressantes em cursos de ensino superior sentem dificuldade em se adaptar à nova modalidade de ensino. Nesse contexto, o evento da Semana do Calouro é realizado pelos discentes do grupo PET de Ciência da Computação da Universidade Federal do Maranhão acompanhados por professores como uma atividade de integração aos novos discentes do curso de Ciência da Computação. Este artigo relata a experiência de aplicar diversas atividades com o intuito de esclarecer as dúvidas geradas pelo ingresso no novo ambiente, bem como aumentar a visibilidade dos contextos do curso. Ao término das atividades, o feedback dos discentes apontou para a utilidade das mesmas para conhecer as oportunidades dentro da universidade em termos de projetos, pesquisas e áreas de atuação, assim como soluções para problemas que surgiram durante sua execução.

\section{Introdução}

A entrada em uma Instituição de Ensino Superior costuma ser um momento de dúvida e curiosidade por parte dos novos alunos. Nesse contexto, o Programa de Educação Tutorial (PET) do curso de Ciência da Computação (PETComp) da Universidade Federal do Maranhão (UFMA) visa apoiar a melhoraria da qualidade da graduação por meio de atividades relacionadas ao ensino, pesquisa e extensão [Lucena et al. 2018]. Dentro das ações do PETComp, existe a preocupação em fornecer aos discentes do primeiro período da graduação, um primeiro contato de integração com o novo paradigma ao qual estarão submetidos ao decorrer da graduação. Com esse intuito de acolhê-los e direcioná-los dentro do novo curso, o PETComp criou um evento chamado Semana do Calouro. Este tipo de 
evento é proposto para apresentar as diversas oportunidades dentro da instituição e tirar eventuais dúvidas sobre como proceder para resolver problemas que os novos discentes venham a enfrentar [Teixeira et al. 2008].

Segundo Santos et al. (2014), o ato de recepcionar os novos discentes é interpretado como uma questão de hospitalidade e integração. Os relatos de discentes participantes mostram que esta atividade também os incentiva a permanecer no curso, já que a alta evasão de estudantes na área de computação é um problema grave decorrente das falhas no processo de formação [Vasconcelos e Andrade 2018]. Nesse contexto, um dos objetivos é fazer os discentes se interessarem por pesquisas científicas, se iniciarem no mercado de trabalho e estabelecer um vínculo entre os colegas de curso, o que consequentemente favorece a interação entre os envolvidos [Carvalho et al 2018]. Neste artigo, é descrito o processo de planejamento e avaliação do evento da Semana do Calouro realizado no contexto da UFMA. Esta atividade foi planejada a partir da visão de alunos veteranos do Curso de Ciência da Computação participantes do Programa de Educação Tutorial em Computação (PETComp). Ao concluir o evento, o mesmo foi avaliado pelos novos discentes participantes que forneceram sugestões do que melhorar para futuras execuções do evento.

\section{Metodologia}

A Semana do Calouro é um evento criado e executado pelo grupo PETComp voltado para os discentes ingressantes no Curso de Graduação em Ciência da Computação da UFMA. Esta atividade vem sendo executada pelo grupo PETComp há mais de três anos, mas não tinham sido coletadas informações sobre a percepção dos discentes quanto à atividade e o seu impacto no início do curso de graduação. Neste artigo, é relatado o processo de execução desta atividade no primeiro semestre de 2020 .

No processo de planejamento foi definido um cronograma de atividades que incluíssem três dias. Este quantitativo de dias foi proposto através de discussões com a coordenação do curso e disponibilidade dos discentes para participação nas atividades. Após uma seção de chuva de ideias, os discentes do grupo PETComp decidiram fazer um total de cinco atividades distribuídas ao longo dos dias: (1) seção de tira-dúvidas e apresentação de dicas sobre a Universidade e o Curso; (2) Dinâmicas de apresentação entre os discentes; (3) Dinâmicas de Integração; (4) Tour de Laboratórios de Pesquisa; e (5) Aula de Reforço de Conteúdos de Matemática e Lógica que eram vistos durante o ensino médio. A seguir, são descritos detalhes de cada uma das atividades.

A atividade intitulada Tira Dúvidas tem como objetivo responder às dúvidas mais frequentes dos novos discentes, em relação aos horários, locais de aula e sobre as funções e formas de uso Sistema Acadêmico, o qual é fundamental para a vida acadêmica dos alunos. Nesta atividade também foram apresentadas algumas instituições relacionadas ao curso de Ciência da Computação da UFMA. O representando institucional da Sociedade Brasileira de Computação (SBC) apresentou o que era um curso de computação, dados sobre a SBC e informações sobre ensino, pesquisa e extensão. O coordenador do curso também proferiu uma palestra com a finalidade de esclarecer as características do Curso de Ciência da Computação e o contexto da universidade de forma geral, assim como atividades extracurriculares, requisitos para aprovação no curso, entre outros. Logo depois, houve a apresentação do grupo PETComp realizada por um representante discente do grupo. Nesta apresentação, foi informado o objetivo do programa PET, os projetos que estão em andamento, os que já foram realizados pelo grupo e o impacto do grupo PET no curso e na 
formação dos discentes que participam do mesmo. Ocorreu também a exposição da empresa júnior do curso, suas diretrizes de funcionamento, o edital para o processo seletivo e seus projetos. Finalmente, houve a apresentação da companhia atlética do curso com o intuito de realçar atividades esportivas dentro da Universidade.

Durante a realização das dinâmicas de auto apresentação e integração, os discentes puderam conhecer os novos colegas de turma. As dinâmicas foram sugeridas pelos discentes veteranos do curso e foi seguida uma ordem aleatória, garantindo que todos os discentes novatos pudessem participar do processo de apresentação e integração. $\mathrm{Na}$ primeira dinâmica, o aluno deveria se apresentar trazendo pontos como: nome, idade, escola ao qual estudou anteriormente e por que escolheu o curso. Na segunda dinâmica, o objetivo era aprender um fato sobre os colegas de turma. Nessa dinâmica foi formado um semicírculo no auditório em que a primeira pessoa em uma das extremidades deveria falar seu nome e algo do que gosta, e então o próximo participante teria que falar as informações dos anteriores e a seguir suas próprias, até que o último viesse a proferir os seus dados e de todos os alunos.

Durante a visita aos laboratórios, cada laboratório visitado contava com a presença de um professor coordenador, ou algum pesquisador que conduzia uma apresentação sobre a sua área de pesquisa, bem como explicações sobre os projetos em andamento e os já finalizados. Neste momento, os discentes pertencentes aos laboratórios conversavam com os novos estudantes sobre o trabalho realizado no dia a dia e os tópicos de pesquisa nas diversas áreas do Curso de Ciência da Computação da UFMA. Entre os tópicos explicados, os discentes tiveram palestras curtas sobre: engenharia de software, interação humano computador, redes de computadores, inteligência artificial, processamento digital de imagens, computação ubíqua, robótica, entre outros. Além disso, houve uma palestra realizada por um professor do curso sobre um tema atual na área de computação. Neste ano, a palestra teve como tema principal: "Problemas éticos da Inteligência Artificial".

Finalmente, houve uma aula em que foram realizadas atividades avaliativas, relembrando conceitos de matemática aplicados à computação, com o intuito de relembrar conteúdos vistos durante o ensino médio e que seriam aplicados no ensino de computação. Estes temas foram escolhidos pelos discentes do grupo PETComp considerando as disciplinas que eles cursaram. A Figura 1 apresenta alguns dos momentos registrados do evento: visita aos laboratórios, dinâmicas em grupo e palestras.

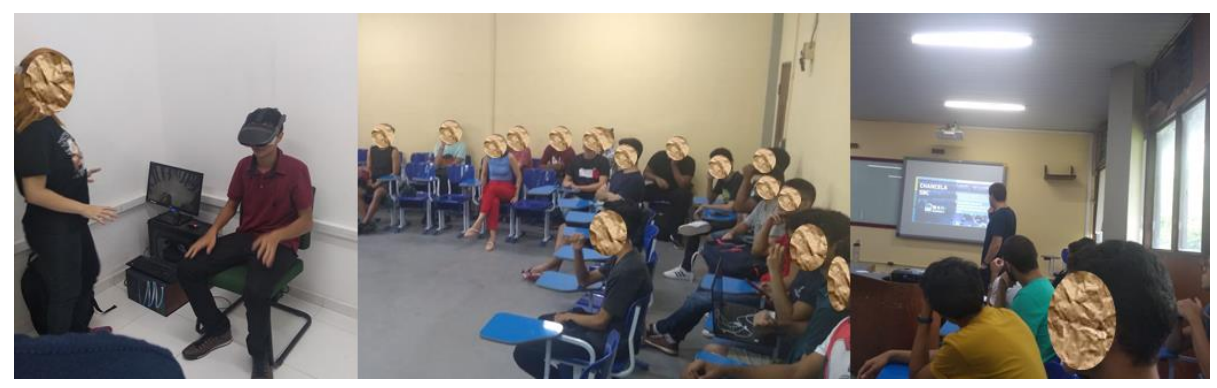

Figura 1 - Registro das atividades realizadas durante a semana do calouro.

Ao final da realização das atividades foi proposto o preenchimento de um formulário, que tinha como principal objetivo avaliar a satisfação dos discentes quanto a programação planejada para a Semana do Calouro, indicando seu nível de satisfação com as atividades em uma escala de 1 a 5 , sendo 5 muito satisfeito e 1 muito insatisfeito. No mesmo formulário encontrava-se uma seção de sugestões onde o discente poderia expressar sua opinião e propor melhorias para cada atividade realizada, tal como sugerir novas atividades. 


\section{Resultados e Discussão}

Dos 46 ingressantes no curso de Computação, 35 discentes participaram de pelo menos um dos dias da semana. Destes alunos, apenas 15 participaram integralmente das atividades oferecidas. Após a divulgação do questionário, somente 16 discentes preencheram o mesmo. Os resultados da avaliação da semana do calouro são baseados na análise das respostas ao questionário por parte destes discentes.

Os alunos que preencheram o questionário tinham em média 18 anos (idade mínima de 17 e máxima de 24 anos). Embora agrupadas em atividades macro, as atividades foram avaliadas no questionário especificando cada atividade específica executada durante a semana do calouro, como apresentado na Seção 2. A Tabela 1 apresenta os resultados da avaliação por parte dos discentes, indicando: a atividade, a duração aproximada da mesma, o total de alunos que participou da atividade e respondeu ao questionário, e a mediana, desvio padrão, valor mínimo e valor máximo das notas de 1 a 5 atribuídas pelos discentes.

Tabela 1 - Preferência dos discentes pelas atividades da recepção dos calouros

\begin{tabular}{|c|c|c|c|c|c|}
\hline $\begin{array}{l}\text { Quanto a atividade a seguir contribuiu } \\
\text { para sua integração e conhecimento } \\
\text { sobre o curso de ciência da } \\
\text { computação? }\end{array}$ & $\begin{array}{l}\text { Total de } \\
\text { Participantes que } \\
\text { Respondeu }\end{array}$ & Mediana & $\begin{array}{l}\text { Desvio } \\
\text { Padrão }\end{array}$ & Mínimo & Máximo \\
\hline Tira Dúvidas com os Discentes (1h) & 11 & 5 & 0,47 & 4 & 5 \\
\hline Dinâmica de Auto-apresentação (1h) & 11 & 5 & 0,40 & 4 & 5 \\
\hline Dinâmica de Integração (1h) & 11 & 5 & 0,30 & 4 & 5 \\
\hline Apresentação da SBC (1h) & 12 & 5 & 0,62 & 3 & 5 \\
\hline $\begin{array}{l}\text { Apresentação do Curso com a } \\
\text { Coordenação }(2 \mathrm{~h})\end{array}$ & 13 & 5 & 0,28 & 4 & 5 \\
\hline Apresentação do PETComp $(0,5 \mathrm{~h})$ & 12 & 5 & 0,65 & 3 & 5 \\
\hline Apresentação da Empresa Junior $(0,5 \mathrm{~h})$ & 12 & 5 & 0,65 & 3 & 5 \\
\hline Apresentação da Companhia Atlética (1h) & 12 & 5 & 1,38 & 1 & 5 \\
\hline $\begin{array}{l}\text { Questionário de Lógica e Matemática para } \\
\text { computação }(1 \mathrm{~h})\end{array}$ & 14 & 4,5 & 0,74 & 3 & 5 \\
\hline $\begin{array}{l}\text { Aula sobre tópico atual em computação } \\
\text { "Problemas Éticos da IA" (2h) }\end{array}$ & 14 & 5 & 0,27 & 4 & 5 \\
\hline Visita aos Laboratórios (4h) & 16 & 5 & 0,54 & 3 & 5 \\
\hline
\end{tabular}

Os resultados indicam que ao todo, as atividades realizadas durante a semana do calouro tiveram alto índice de aprovação pelos participantes. Ao perguntar dos participantes qual das atividades eles preferiram, eles indicaram a visita aos laboratórios, a aula sobre um tópico atual e a palestra da coordenação sobre o curso, nessa ordem de preferência. Tais resultados indicam o interesse dos novos discentes nas informações e oportunidades pertinentes à graduação, assim como em conhecer os tópicos que estudarão.

Para obter mais informações sobre o que os discentes gostaram mais na semana do calouro e o que poderia ser melhorado, o questionário também apresentou questões abertas. Com o feedback obtido, foi possível perceber que a Semana do Calouro no início do período letivo é considerada pelos discentes novatos como uma fonte de informações importantes para sua formação acadêmica. Além disso, foram obtidos indícios sobre a demanda de melhorias organizacionais no evento, como uma maior divulgação do evento, comunicação entre o PETComp e os colaboradores pertinentes às atividades realizadas e o planejamento 
criativo das atividades, para incluir atividades diferenciadas. Alguns exemplos de comentários feitos pelos alunos são: "gostei mais do LABTOUR, pois não só me deu uma noção da proporção e estruturação do campus como também me inseriu nas diversas áreas e eventos/atividades disponíveis no curso"; "gostei do questionário de lógica e matemática, porque ajudou a ter noção de quais assuntos são mais importantes"; e "pediria para que a coordenação divulgue melhor [o evento] para os calouros, assim facilitaria a localização do aluno dentro do seu próprio curso".

\section{Conclusão}

Este artigo apresentou o processo de planejamento, execução e avaliação da Semana do Calouro organizada pelo grupo PETComp da UFMA. Este evento proporcionou a ambientação dos discentes, sanando as dúvidas, proporcionando a visibilidade do curso e suas oportunidades. Além disso, foi possível identificar oportunidades de aprimoramento do evento, possibilitando a prevenção de problemas semelhantes nas suas edições futuras. Pretende-se como trabalho futuro, investigar o impacto do evento a longo prazo, avaliando a percepção dos discentes sobre o curso e identificar se alguma informação adicional pode ser apresentada, de modo a sanar as dúvidas dos participantes com relação à área de computação, às possibilidades acadêmicas dentro da universidade, o mercado de trabalho, entre outros.

\section{Referências}

Carvalho, L. S. G., Santos, A. L. M., Nakamura, F. G., Oliveira, E. H. T. Detecção precoce de evasão em cursos de graduação presencial em Computação: um estudo preliminar. WORKSHOP SOBRE EDUCAÇÃO EM COMPUTAÇÃO (WEI), 27. 2019.

de Lucena, L. B., de Andrade, G. L. C., Soares, E. D. F. A., dos Santos Júnior, W. S., de Oliveira, Á. G. G., Batista, L. M. D. S. D., ... \& de Lima, R. W. (2018, July). As ações do pet no desenvolvimento do curso de Ciência da Computação. In Anais do XXVI Workshop sobre Educação em Computação. SBC.

Pereira, E. A. D. S., Junior, G. B., Costa, Y. D. J. S. \& Mendes, J. C. (2018). LabTour: um guia de incentivo à pesquisa. VII Jornada Informática do Maranhão (JIM).

Santos, M. M. C.; Perazollo, O. A.; Pereira, S. A hospitalidade numa perspectiva coletiva o corpo coletivo acolhedor. In: Santos, M. M. C.; Baptista, I. (org.). Laços sociais: por uma epistemologia da hospitalidade. Caxias do Sul: Educs, 2014.

Santos, M. S., Chaves, A. R. F., Ferreira, R. S. S. A, Moreira, S. F. D. C., Souza, M. R. D. \& Borges, C. J. (2018). Acolher mais: Recepção dos calouros do curso de graduação em enfermagem. Revista Eletrônica Graduação/Pós Graduação em Educação UFG/REG, 2018.

Silva, J. J., Júnior, J. C. S., Araújo, A. C. D. C., Costa, H. M., Cabrejos, L. J. E. R. Motivando alunos do ensino médio e graduação para a computação. XXIV Encontro Nacional dos Grupos PET (ENAPET 2019).

Teixeira, M. A. P., Dias, A. C. G., Wottrich, S. H., Oliveira, A. M. Adaptação à universidade em jovens calouros. Revista Semestral da Associação Brasileira de Psicologia Escolar e Educacional, 2018.

Vasconcelos, V., \& Andrade, E. (2018, July). Análise da Evasão de Alunos na Licenciatura em Computação. In Anais do XXVI Workshop sobre Educação em Computação. SBC. 